\title{
The Relationship Between EFL Students' Word-Knowledge in a Text and Their Reading Comprehension as Demonstrated by Saudi University Students
}

\author{
Farooq AlTameemy ${ }^{1}$, Amer Daradkeh ${ }^{1} \&$ Abdulhameed Alhamod $^{1}$ \\ ${ }^{1}$ English Department, Preparatory Year Deanship, Prince Sattam bin Abdulaziz University, Kingdom of Saudi \\ Arabia \\ Correspondence: Farooq AlTameemy, English Department, Preparatory Year Deanship, Prince Sattam bin \\ Abdulaziz University, Kingdom of Saudi Arabia.
}

Received: March 12, 2018

Accepted: April 10, $2018 \quad$ Online Published: May 15, 2018

doi:10.5539/jel.v7n4p236

URL: https://doi.org/10.5539/jel.v7n4p236

\begin{abstract}
This study reports the outcomes of research investigating the relationship between two variables; percentage of word knowledge in an academic English text and reading comprehension scores the participants got for the same text. The study was conducted at Prince Sattam Bin Abdulaziz University, Preparatory Year Deanship, during the first semester of 2017-2018. Seventy-one Saudi male students participated in the study. They came from four groups of students selected from the Preparatory Year population to represent four various levels of English (Groups one, seven, fourteen and seventeen) based on their achievement in the placement test. Data was collected using two instruments: two word-meaning association test-lists and a reading comprehension test. The results showed that there is a statistically significant correlation $(\mathrm{r}=.702)$ between percentage of known words and reading comprehension in general i.e., for all the participants. The effect of word knowledge on reading comprehension was very high $\mathrm{R}$ square $=.49$. However, results for the groups separately showed that correlation was positive but not statistically significant for the higher levels i.e., groups one and seven. Also, there was a low effect of word knowledge on comprehension. For the lower levels i.e., groups 14 and 17, the correlation was positive and statistically significant. Results also showed a very high effect of vocabulary knowledge on reading comprehension.

Based on the results and analysis of the study, the researchers provided recommendations that will help improve reading curriculum selection and English teaching practices, and suggestions for deeper research into the topic that will include female students and other related concepts.
\end{abstract}

Keywords: word knowledge, vocabulary size, vocabulary breadth, reading comprehension

\section{Introduction}

Reading as a complex, dynamic and multidimensional process (Anderson, 2000) has taken superiority as a language skill in an academic context (Grabe, 1991). In the instructional process, reading affects language learning remarkably. According to Mikulecky (2008), effect goes to different language learning aspects such as the use of textbooks in general, writing, developing vocabulary, dealing with grammar and structure etc. Scholarly efforts confirmed that there is a strong relationship between reading and comprehension. Even though reading has many purposes, scholars such as Linan-Thompson \& Vaughn (2007) and Grabe \& Stoller (2002) viewed 'comprehension' as the most important purpose of reading that also aids the other purposes. Reading in its nature is not only the process of mouthing words but seeks to get what is beyond the written symbols. Thus, the reader interacts with the text using his linguistic knowledge i.e. vocabulary and non-linguistic knowledge for comprehension.

Reading comprehension is inextricably connected to vocabulary knowledge. The relationship between both is, in fact, reciprocal (Güngör \& Yayli, 2016). Readers require vocabulary to get meanings from any reading text and by reading they learn new words (Eskey, 2005). The aforementioned relationship motivated researchers, such as Nation (2006) and Nation \& Angell (2006) and others, to conduct studies on the effects of reading comprehension on vocabulary size. Other studies that also investigated the effects of vocabulary size on reading comprehension are going to be discussed in the literature review. As a result, many researchers considered 
vocabulary the best predicator of reading comprehension (Nation, 2006; Qian, 2002; Bernhardt \& Kamil, 1995; Ulijn \& Strother, 1990).

From a similar perspective, this study was conducted to investigate the relationship between vocabulary size that Saudi University students have in a reading text, not their vocabulary knowledge as a whole, and their reading comprehension scores of academic passages written in English. Results will, hopefully, trigger new ideas and shed more light onto the effect of word knowledge on comprehension.

\section{Research Questions}

The current study addressed the following questions:

1) What is the relationship between percentage of known words in an academic text and reading comprehension scores in the same text?

2) Does the increase in knowledge of word-meaning lead to statistically significantly better reading comprehension? (Measured by better scores on comprehension test)

3) Is the relationship the same among low-level \& high-level students?

\section{Research Objectives}

The ultimate goal of this study is to explore the relationship between text-based word knowledge and reading comprehension. The researchers looked at the correlation between the percentage of learners' word-knowledge and their reading comprehension scores. In addition, they investigated whether the increase in word-knowledge lead to a relative increase in reading comprehension. Last, they investigated the groups separately to see that relationship for lower and higher level groups.

\section{Significance of the Study}

The significance of this study stems from the following points: 1) There are very few studies conducted in Saudi Arabia to identify the correlation between vocabulary size and reading comprehension. Thus, it is a seminal attempt to fill this gap in Middle Eastern academic classrooms using English as a foreign language. In addition, it strengthens the previous findings in the same field. 2) Although this issue, as shown from the literature below, has been addressed thoroughly before, this study is unique as it is focused on the Saudi context as well as on foundation/Preparatory year English program students. Findings will help gear curricula selection decisions with the increase in students' comprehension in mind. In addition to that, it focuses on EFL methodology that utilize methods of teaching that assist, based on the findings in improving students reading comprehension, a skill that will be so much needed when they join their academic program the following year. 3) The results of the current study will serve as recommendations for curriculum designers in Saudi Arabia, as well as the EFL community in general, to take into consideration the structural relationship between vocabulary knowledge and reading comprehension; and 4) the study's findings will facilitate the process of instruction in which teachers are aware that vocabulary is a good predicator of reading comprehension.

\section{Literature Review}

Laufer (1989) conducted a study to identify the required vocabulary to achieve $55 \%$ on a reading comprehension test. Data was collected from 100 first-year university students, who have Arabic or Hebrew as their native language. Participants were given double tasks: First to identify words they did not know in the text and adjust their answers using a translation test, and the second was a reading comprehension test. The results showed that the participants who knew $95 \%$ of the text words were better able to score $55 \%$ on reading comprehension test, and based on Ostyn \& Godin's research (1985), Laufer pointed out that those students knew approximately 5,000 words. Although, a pioneer in addressing this issue, Nation (2013, pp. 144-148) criticized it and brought about doubt to apply the results of Ostyn and Godin's study to English as their results were based on Dutch language and they used different genres of texts. In addition to that, setting the threshold, $55 \%$, set in the study, was low. Schmitt, Jiang \& Grabe (2011) pointed out that reading comprehension out of 55\% is lower than what students want to achieve in reading comprehension tests.

$\mathrm{Hu} \&$ Nation (2000) studied the relationship between the lexical coverage and reading comprehension of fiction texts. To examine the effect of density of unknown vocabulary on reading comprehension, four versions of the text $80 \%, 90 \%, 95 \%$ and $100 \%$ were prepared by replacing the words that are less frequent by nonsense words and simplification of the text. The participants were 66 adults attending a pre-university English course. They attended university in an English speaking country, yet they had various mother tongues. They had a variety of language backgrounds. The subjects read a 673-word story and completed two tests: fourteen-item multiple-choice (MCQs) and twenty-seven questions cued written recall (WR) tests to show their understanding 
of the main ideas and supporting detail. The findings of comparing the four versions of vocabulary coverage to reading comprehension scores in multiple choice test showed that: Fifteen out of seventeen subjects, who read the $100 \%$ version, got at least 12 correct questions out of fourteen. In other words, twelve correct answers referred to the adequate comprehension. Only six out of seventeen subjects, who read the $95 \%$ version, got twelve and more correct answers, so this version is not adequate for most students to gain good comprehension. Only four out of sixteen subjects, who read the $90 \%$ version, got twelve and more correct answers. The results of reading $90 \%$ and $95 \%$ versions were quite similar. All subjects, who read the $80 \%$, got less than twelve correct answers so this version is the bottom standard. The range of scores on the cued written recall test for subjects, who read the four versions of the text, reported that most of the subjects, who read $100 \%$ version, achieved adequate comprehension. The minority of subjects, who read the $95 \%$ version did, fewer of subjects, who read $90 \%$ version, did and no subjects, who read $80 \%$ version, gained adequate comprehension. The research supported the notion that $98 \%$ coverage may be required to gain adequate comprehension for pleasure. As a general conclusion, this study confirms that reading comprehension scores increase to a certain degree as the knowledge of words increases. In spite of this fruitful effort to investigate the relationship between vocabulary coverage and reading comprehension, this study presented its results based on only four versions of the text. In addition, the researchers believe that the number of subjects who read each version is small.

Laufer \& Ravenhorst-Kalovski (2010) explored the relationship between learners' vocabulary size, lexical text coverage and their reading comprehension. They also tried to define 'adequate reading comprehension' and find its threshold with regard to coverage and vocabulary size. The participants of the study were 745 academic-college students in different departments. They were taking a course in English to improve their reading comprehension. One hundred sixty-seven participants were native speakers of Arabic, 73 of Russian and 495 of Hebrew. To investigate the three variables, the researchers used three instruments: First, the learners' reading comprehension was measured by the English part of the Psychometric University Entrance Test. To measure Learners' vocabulary size, the researchers used the revised version of Nation's (1983) Vocabulary Levels Test. The third variable "lexical coverage" was measured by three tests analyzed by a new version of Vocabulary Profile. The findings showed that learners with less frequent vocabulary have smaller text coverage, and that increasing in vocabulary size and lexical coverage is beneficial for reading comprehension. This study proposed two thresholds: the optimal one suggested that the knowledge of 8000 word families indicates $98 \%$ coverage including proper nouns. The minimal one suggested that $4000-5000$ word knowledge predicates $95 \%$ coverage including proper nouns.

Schmitt, Jiang \& Grabe (2011) conducted a study that aimed at answering three questions. First was about the relationship between percentage of known words in a text and comprehension level of the same text. The second question investigated the possibilities of reading comprehension when the percentage of vocabulary coverage is low, and the third, which is not related to this study, investigated the effect of background knowledge about the topic of the text on the relationship between vocabulary coverage and reading comprehension. The participants were 661 from 8 different countries. They were different in level, intermediate to very advanced; different in age, 16 to 33 years old; and different in gender 241 male and 420 female students. The findings showed that the relationship between percentage of known words and level of reading comprehension is linear at least with the vocabulary coverage of $90 \%$ to $100 \%$. Thus, having more known words means gaining better comprehension. The findings of the second question showed that the learners with low levels of vocabulary coverage had lower levels of comprehension of the text. On the other hand, knowing $100 \%$ of the words in the text does not mean gaining $100 \%$ of reading comprehension. This study confirmed Laufer \& Ravenhorst-Kalovskis' (2010) study that $98 \%$ level of lexical coverage is reasonable for sufficient reading comprehension, but it did not find a vocabulary threshold where certain vocabulary knowledge causes a serious increase in reading comprehension.

Unlike Schmitt et al. (2011), Mahmoudi (2017) who investigated the relationship between background knowledge of the topic and reading comprehension of Iranian EFL students, found out that there is no effect of background knowledge and that the proficiency in the language is what matters.

Güngör \& Yayli (2016) focused on the required vocabulary size for reading comprehension of expository text in the Turkish EFL context. This study scrutinized the probability of threshold level of lexical coverage between adequate and inadequate reading comprehension, the relationship between lexical coverage and reading comprehension and necessary percentage of coverage to achieve adequate comprehension of expository texts. To collect data, the study used two instruments: 1) a vocabulary checklist that consisted of 168 words completed by the participants to measure the number of words they knew. And 2) reading texts and comprehension tests: two expository texts were selected based on student, text and context factors. The findings showed that there was no specific critical point at which comprehension increases remarkably. The vocabulary coverage and text 
comprehension increased gradually at level $88 \%$, but the increase started to go slowly at the levels of $90 \%, 92 \%$ and $96 \%$ coverage. The correlation between text-based vocabulary coverage and the reading comprehension level was moderate and the relationship was linear for the first 8000 words vocabulary coverage.

Moinzadeh \& Moslehpour (2012) took another turn in investigating the correlation between vocabulary and reading comprehension. They studied vocabulary breadth and depth and their correlation to comprehension. Their finding was that there was a positive correlation in general. However, their study results indicated that vocabulary breadth was a stronger predictor of reading comprehension. This finding conflicted with an earlier study of Qian (1999) which found that vocabulary breadth was a weaker predictor of reading comprehension.

Kang, Kang \& Park (2012) study, which found a strong relationship between vocabulary knowledge and reading comprehension, affirmed Qian's (1999) findings as they found out that vocabulary depth proved more effective than vocabulary breadth in predicting reading comprehension. The study was conducted on ninety-eight Korean High school students.

Reed, Pestcher, \& Foorman (2016) took a little different perspective in addressing the issue as they added the spelling factor to the correlation and investigated both vocabulary knowledge and spelling on both English and other language learners for 2813 students from the state of Florida. Results showed that vocabulary knowledge accounted for more reading comprehension than spelling.

In a very recent study, Hacking \& Tschirner (2017), having noticed in the literature that many studies have shown a positive correlation between vocabulary knowledge and reading comprehension of English text, investigated this correlation for 48 American students studying Prussian. Findings were similar with statistically significant correlation.

The current study is going to focus on investigating the correlation between word-knowledge i.e. word meaning and reading comprehension in the Saudi context. All the participants were male Saudi University students and all words in the vocabulary test were taken from two academic texts and reading comprehension test on the same texts.

\section{Methodology}

\subsection{Participants}

The current study was conducted at the Preparatory Year Deanship at Prince Sattam Bin Abdulaziz University. Participants were 71 Saudi preparatory-year male students during the first semester of 2017-2018. In their English program, for the first semester, participants take a total of 12 hours English instruction per week that is divided into 6 hours for reading and the other 6 for writing. Instruction is offered by native and non-native English instructors. The sample of the study was 71 male undergraduate students, aged 18-20 years old, and they studied English in private and public schools for 7 to 10 years prior to their university admission. The sample was groups $1,7,14,17(18,23,16$, and 14 students respectively). Students in the preparatory year are grouped based on their placement test with 1 being the top and going down to group 19. Students are divided with 20-25 students per class. English instruction in the preparatory year, along with the sciences classes, is meant as a foundation year before students were admitted to their either medical or engineering fields at the university.

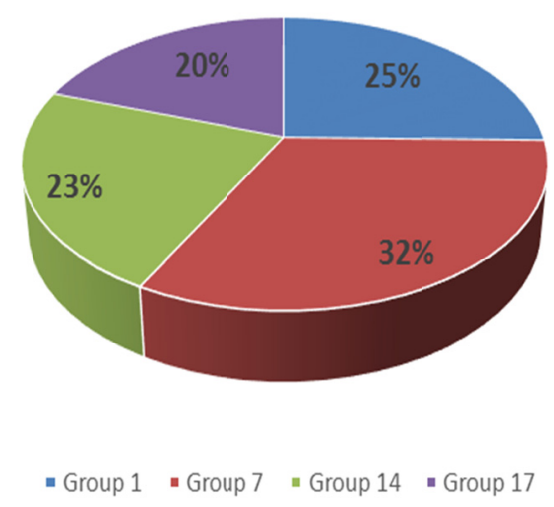

Figure 1. Distribution of participants according to groups 


\subsection{Instrument \& Procedures}

The study used two instruments. The first was two lists of words taken from TOEFL reading texts about rainforests and human memory used by Alsamadani (2009). These TOEFL tests are highly reliable and valid (Pierce, 1994). Initially, the list ran through a pilot test with a group of 20 students other than the participants. In the pilot session, time needed was observed in addition to issues with length of the text and the variety of words used. Various native and non-native speakers teaching in the PYD, at Prince Sattam Bin Abdulaziz were also consulted. With notes and observation from the pilot test of the list and the ideas collected, it was decided to minimize the number of columns in the words test list. Initially, it contained the following headings: Words, Check if you know the word, Meaning in English, Meaning in Arabic. After the pilot study, the Check column was eliminated, and the participants had the option to write the meaning in Arabic or English. The second instrument was a reading comprehension test. It contained two reading passages of about 215 words each and each was followed by 7 comprehension questions. The readings were the two TOEFL texts from which the words-lists, i.e., first instrument, were extracted. Participants of the study went through both tests i.e. words meaning test \& comprehension reading test on two different days in the same week.

\subsection{Data Collection and Analysis}

Collected data from the first test i.e. vocabulary test was checked. The result was converted into percentage of the total maximum correct number. The same was done to the comprehension test. In both, group number reflects the level of the students in a descending format (group 1 is the highest in level and 17 is the lowest). Both excel and SPSS were used in analyzing the data.

\section{Results}

In the following, results of the study will be explained starting by doing the analysis for all the student participants, then by doing it by group ( 4 groups were selected based on the level with group 1 being the top followed by 7, 14, 17 respectively).

\subsection{All the Student Participants}

Table 1. Descriptive statistics: all student participants

\begin{tabular}{lcll}
\hline & Mean & Std. Deviation & N \\
\hline All Students Vocabulary Test Results & 52.48619 & 21.147203 & 71 \\
All Students Reading Test Results & 49.89940 & 17.349644 & 71 \\
\hline
\end{tabular}

A two-tailed Pearson correlation analysis was conducted to find out if there is any statistically significant correlation between the percentage of known words in an academic text and reading comprehension scores for students in the Preparatory Year Deanship at Prince Sattam Bin Abdulaziz University. This was done for all the participant students (table 1).

Table 2 shows that there is a statistically significant correlation between percentage of known words and reading comprehension $(\mathrm{r}=.702)$. The correlation is strong and positive according to the coefficient of correlation $(\mathrm{r}=0$ no correlation, $\% 0<\mathrm{r}<\% 30$ weak correlation, $\% 30<=\mathrm{r}<\% 70$ medium correlation, $\% 70<=\mathrm{r}<\% 100$, $\mathrm{r}=1$ perfect correlation) as the table demonstrates with significant value less than 0.05 which is less than $\alpha(0.05)$.

Table 2. Correlation between percentage of known words in an academic text and reading comprehension scores: all participants

\begin{tabular}{llll}
\hline & & All Students Vocabulary Test Results & All Students Reading Test Results \\
\hline \multirow{4}{*}{ All Students Vocabulary Test Results } & Pearson Correlation & 1 & $.702^{* *}$ \\
& Sig. (2-tailed) & & .000 \\
& $\mathrm{~N}$ & 71 & 71 \\
& Pearson Correlation & $.702^{* *}$ & 1 \\
All Students Reading Test Results & Sig. (2-tailed) & .000 & \\
& $\mathrm{~N}$ & 71 & 71 \\
\hline
\end{tabular}

Note. ${ }^{* *}$. Correlation is significant at the 0.05 level (2-tailed). 
A regression analysis was conducted to investigate the effect of known vocabulary, in general based on all participants, on reading comprehension. The effect (table 3) is very high as R Square is .493. In other words, .507 can be ascribed to other factors.

Table 3. Effect of known-words knowledge on reading comprehension: all participants

\begin{tabular}{lllll}
\hline Model & $\mathrm{R}$ & $\mathrm{R}$ Square & Adjusted R Square & Std. Error of the Estimate \\
\hline 1 & $.702^{\mathrm{a}}$ & .493 & .485 & 12.446878 \\
\hline a. Predictors: (Constant), All Participants Vocabulary Test All Participants \\
\hline
\end{tabular}

\subsection{Group One}

A two-tailed Pearson correlation analysis was conducted to find out if there is any statistically significant correlation between the percentage of known words in an academic text and reading comprehension scores for students in group 1 (table 4).

Table 4. Descriptive statistics: group 1

\begin{tabular}{llll}
\hline & Mean & Std. Deviation & $\mathrm{N}$ \\
\hline Vocabulary Test Results G1 & 78.9441 & 11.34618 & 18 \\
Reading Test Results G1 & 68.6508 & 13.67143 & 18 \\
\hline
\end{tabular}

Table 5 shows that there is a correlation between percentage of known words and reading comprehension $(\mathrm{r}=.306)$. The correlation is medium and positive according to the coefficient of correlation as the table demonstrates with significant value less than 0.05 which is less than $\alpha(0.05)$.

Table 5. Correlation between percentage of known words in an academic text and reading comprehension scores: group 1

\begin{tabular}{llll}
\hline & & Vocabulary Test G1 & Reading Test G1 \\
\hline \multirow{3}{*}{ Vocabulary Test G1 } & Pearson Correlation & 1 & .306 \\
& Sig. (2-tailed) & & .217 \\
& N & 18 & 18 \\
& Pearson Correlation & .306 & 1 \\
Reading Test G1 & Sig. (2-tailed) & .217 & \\
& N & 18 & 18 \\
\hline
\end{tabular}

A regression analysis was conducted to investigate the effect of known vocabulary on reading comprehension for group 1. The effect (table 6) is very low as R Square is .093. In other words, .907 can be ascribed to other factors.

Table 6. Effect of known-words knowledge on reading comprehension: group 1

\begin{tabular}{lllll}
\hline Model & $\mathrm{R}$ & $\mathrm{R}$ Square & Adjusted R Square & Std. Error of the Estimate \\
\hline 1 & $.306^{\mathrm{a}}$ & .093 & .037 & 13.41792 \\
\hline
\end{tabular}

\subsection{Group Seven}

A two-tailed Pearson correlation analysis was conducted to find out if there is any statistically significant correlation between the percentage of known words in an academic text and reading comprehension scores for students in group 7 (table 7). 
Table 7. Descriptive statistics: group 7

\begin{tabular}{llll}
\hline & Mean & Std. Deviation & $\mathrm{N}$ \\
\hline Vocabulary Test G7 & 47.9702 & 13.14158 & 23 \\
Reading Test G7 & 45.9627 & 12.52569 & 23 \\
\hline
\end{tabular}

Table 8 shows that there is a correlation between percentage of known words and reading comprehension $(\mathrm{r}=.068)$. The correlation is weak and positive according to the coefficient of correlation as the table demonstrates with sig value less than 0.05 which is less than $\alpha(0.05)$.

Table 8. Correlation between percentage of known words in an academic text and reading comprehension scores: group 7

\begin{tabular}{llll}
\hline & & Vocabulary Test G7 & Reading Test G7 \\
\hline \multirow{3}{*}{ Vocabulary Test G7 } & Pearson Correlation & 1 & .068 \\
& Sig. (2-tailed) & & .757 \\
& $\mathrm{~N}$ & 23 & 23 \\
& Pearson Correlation & .068 & 1 \\
Reading Test G7 & Sig. (2-tailed) & .757 & \\
& $\mathrm{~N}$ & 23 & 23 \\
\hline
\end{tabular}

A regression analysis was conducted to investigate the effect of known vocabulary on reading comprehension for group 7. The effect (table 9) is very low as R Square is .005. In other words, .995 can be ascribed to other factors.

Table 9. Effect of known-words knowledge on reading comprehension: group 7

\begin{tabular}{lllll}
\hline Model & $\mathrm{R}$ & $\mathrm{R}$ Square & Adjusted R Square & Std. Error of the Estimate \\
\hline 1 & $.068^{\mathrm{a}}$ & .005 & -.043 & 12.79045 \\
\hline a. Predictors: (Constant), Vocabulary Test G7 & \\
\hline
\end{tabular}

\subsection{Group Fourteen}

A two-tailed Pearson correlation analysis was conducted to find if there is any statistically significant correlation between the percentage of known words in an academic text and reading comprehension scores for students in group 14 (table 10)

Table 10. Descriptive statistics: group 14

\begin{tabular}{llll}
\hline & Mean & Std. Deviation & $\mathrm{N}$ \\
\hline Vocabulary Test G14 & 40.6077 & 16.68959 & 16 \\
Reading Test G14 & 38.3929 & 13.52121 & 16 \\
\hline
\end{tabular}

Table 11 shows that there is a statistically significant correlation between percentage of known words and reading comprehension $(\mathrm{r}=.745)$. The correlation is strong and positive according to the coefficient of correlation as the table demonstrates with sig value less than 0.05 which is less than $\alpha(0.05)$.

Table 11. Correlation between percentage of known words in an academic text and reading comprehension scores: group 14

\begin{tabular}{llll}
\hline & & Vocabulary Test G14 & Reading Test G14 \\
\hline \multirow{2}{*}{ Vocabulary Test G14 } & Pearson Correlation & 1 & $.745^{* *}$ \\
& Sig. (2-tailed) & & .001 \\
& $\mathrm{~N}$ & 16 & 16 \\
\multirow{2}{*}{ Reading Test G14 } & Pearson Correlation & $.745^{* *}$ & 1 \\
& Sig. (2-tailed) & .001 & 16 \\
& $\mathrm{~N}$ & 16 & \\
\hline **. Correlation is significant at the 0.05 level (2-tailed). &
\end{tabular}


A regression analysis was conducted to investigate the effect of known vocabulary on reading comprehension for group 14. The effect (table 12) is very high as R Square is .555. In other words, .445 can be ascribed to other factors.

Table 12. Effect of known-words knowledge on reading comprehension: group 14

\begin{tabular}{lllll}
\hline Model & $\mathrm{R}$ & $\mathrm{R}$ Square & Adjusted R Square & Std. Error of the Estimate \\
\hline 1 & $.745^{\mathrm{a}}$ & .555 & .523 & 9.33648 \\
\hline a. Predictors: (Constant), Vocabulary Test G14 & & \\
\hline
\end{tabular}

\subsection{Group 17}

A two-tailed Pearson correlation analysis was conducted to find out if there is any statistically significant correlation between the percentage of known words in an academic text and reading comprehension scores for students in group 17 (table 13).

Table 13. Descriptive statistics: group 17

\begin{tabular}{llll}
\hline & Mean & Std. Deviation & $\mathrm{N}$ \\
\hline Vocabulary Test G17 & 39.4633 & 16.25953 & 14 \\
Reading Test G17 & 45.4082 & 14.17738 & 14 \\
\hline
\end{tabular}

Table 14 shows that there is a statistically significant correlation between percentage of known words and reading comprehension $(r=, 703)$. The correlation is strong and positive according to the coefficient of correlation as the table demonstrates with sig value less than 0.05 which is less than $\alpha(0.05)$.

Table 14. Correlation between percentage of known words in an academic text and reading comprehension scores: group 17

\begin{tabular}{llll}
\hline & & Vocabulary Test G17 & Reading Test G17 \\
\hline \multirow{2}{*}{ Vocabulary Test G17 } & Pearson Correlation & 1 & $.703^{* *}$ \\
& Sig. (2-tailed) & & .005 \\
& N & 14 & 14 \\
\multirow{2}{*}{ Reading Test G17 } & Pearson Correlation & $.703^{* *}$ & 1 \\
& Sig. (2-tailed) & .005 & 14 \\
\hline **. Correlation is significant at the 0.05 level (2-tailed). & 14 & \\
\hline
\end{tabular}

A regression analysis was conducted to investigate the effect of known vocabulary on reading comprehension for group 17. The effect (table 15) is very high as R Square is .494. In other words, .506 can be ascribed to other factors.

Table 15. Effect of known-words knowledge on reading comprehension: group 17

\begin{tabular}{lllll}
\hline Model & R & R Square & Adjusted R Square & Std. Error of the Estimate \\
\hline 1 & $.703^{\mathrm{a}}$ & .494 & .452 & 10.49414 \\
\hline a. Predictors: (Constant), Vocabulary Test G17 & & \\
\hline
\end{tabular}

\section{Discussion}

Generally, the results, presented above, showed that there was a statistically significant correlation between vocabulary knowledge and reading comprehension for the Preparatory Year Deanship students at Prince Sattam Bin Abdulaziz University. The results also showed that there was a high positive effect of vocabulary knowledge on reading comprehension. This correlation and positive effect is in line with previous studies such as Rashidi \& Khosravi (2010) and Li (2015). When correlation and effect were studied for the groups 1, 7, 14, and 17 separately, results were a little different. For the higher level groups i.e., 1 and 7, results showed there was a positive correlation but it was not statistically significant. The positive effect was low with $\mathrm{R}$ square $=.093$ 
and .005 respectively, which means there is a higher percentage for effect of other factors on the participants' reading comprehension. On the contrary, for the lower level participants in groups 14 and 17, the correlation was statistically significant with a very high positive effect of vocabulary knowledge on reading comprehension (with $\mathrm{R}$ square $=0.56$ and .49 respectively). This reflects a higher reliance on knowing the meaning of the vocabulary by lower level students. Similar results were found in studies such as Harkio \& Pietilä (2016).

It is important to point out here that within the higher groups 1 and 7 (same for 14 and 17) results showed an unexpected disparity in the results. Although group 1 is higher in level than group 7, i.e. as per the PYP placement test, results showed that correlation to as well as effect of the vocabulary knowledge on reading comprehension was higher in group 1 than 7 and in 14 than 17. The researchers believe that this can be ascribed to other factors that could not be controlled by the researchers such as the mood of students and their desire to do the study task especially if they were to do an important quiz or work on some other marked project. The time the task was done could be a factor. In addition, there could be other factors. For example, it is allowed for students to move from a lower-level section to a higher one and vice versa to accommodate students' schedule when approved by the deanship.

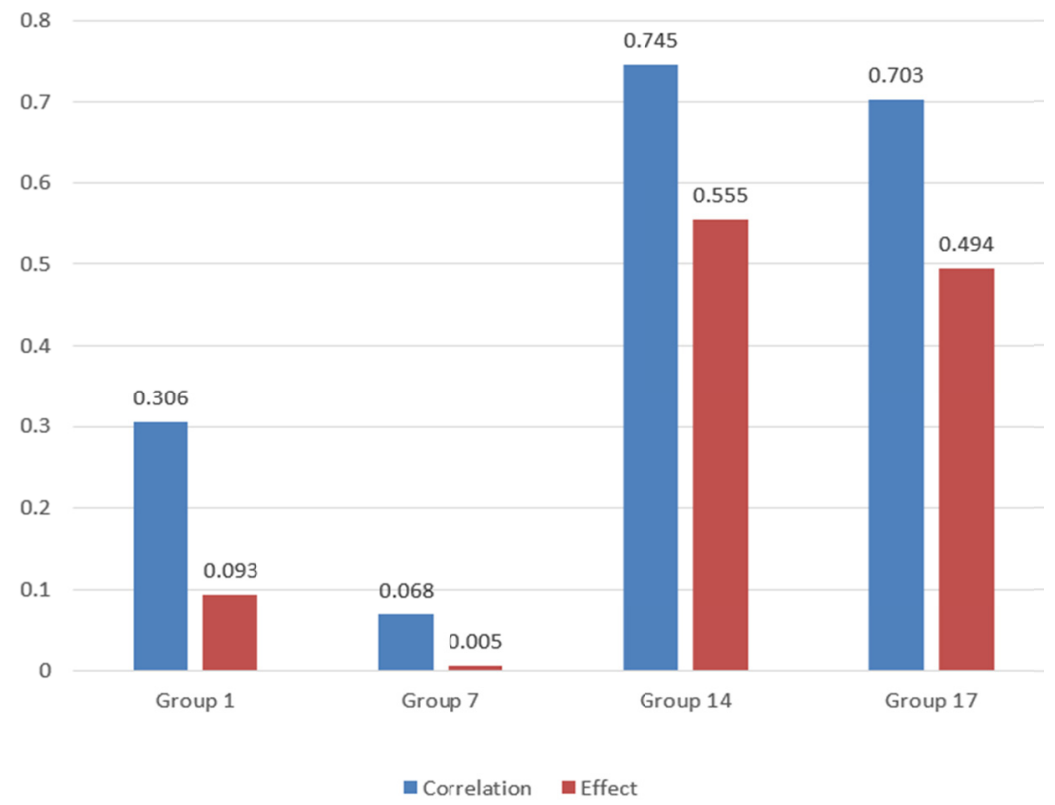

Figure 2. Correlation and effect differences among groups

\section{Conclusions}

From the results pointed out above, it was found that previous knowledge of the vocabulary meaning(s) has a significant positive effect on the language learners' reading comprehension in general. However, this effect is very high when focus is placed on low-level learners. It becomes lower when learners reach higher level of language mastery. With that, it can be concluded that language learners in early stages of learning the language need much more focus on vocabulary and their meanings which will facilitate their reading comprehension.

\section{Recommendations and Future Research}

Based on the results of the study, the researchers make the following recommendations:

1) A focus should be placed on teaching vocabulary extensively to lower levels. While this, according to this research, is needed for the learners' reading comprehension, it is also, a predictor of language improvement in general Rashidi \& Khosravi (2010).

2) A high level of importance needs to be given to vocabulary instruction when designing the English curriculum for the foundation/preparatory year programs. This will lead to better language learning outcomes (Nichols, Mraz, \& Blair, 2012). 
3) A future study should be broad enough to cover the female learners of English, in addition to the students majoring in English language.

4) Another study should explore not only the vocabulary knowledge, here referring mostly to vocabulary size, but also the depth of vocabulary. Studies such as those of Qian (1999) and Zhang \& Yang (2016), found that the depth of vocabulary knowledge was more indicator of reading comprehension. However, Li \& Kirby (2014) did not find a statistically significant difference between size, i.e. breadth, of vocabulary knowledge and depth, yet a stronger effect of depth of vocabulary on reading comprehension. It will be interesting to investigate the depth of vocabulary knowledge and its effect in a Saudi college students' context.

\section{Limitations of the Study}

The study had the following limitations:

1) All the participants in this study were Arab male university students. They shared the same mother tongue, religious norms, social traditions and economic status. And they were all enrolled in the university level foundation classes during the first semester of the preparatory year at Prince Sattam Bin Abd Al Aziz University 2017-2018.

2) The study was text-based in nature in that it investigated the subjects' known words in an academic text rather than their general vocabulary knowledge based on standardized vocabulary size tests.

3) For the sake of this study, it focused on only one level of knowledge i.e. word meaning. A future study will address morphological, syntactic and semantic awareness.

\section{References}

Alsamadani, H. A. (2009). The relationship between Saudi EFL college-level students' use of reading strategies and their EFL reading comprehension (Doctoral dissertation). Ohio University.

Anderson, J. R. (2000). Learning and memory: An integrated approach (2nd ed.). New York: John Willey \& Sons.

Bernhardt, E. B., \& Kamil, M. L. (1995). Interpreting relationships between L1 and L2 reading: Consolidating the linguistic threshold and the linguistic interdependence hypotheses. Applied Linguistics, 16(1), 15-34. https://doi.org/10.1093/applin/16.1.15

Eskey, D. E. (2005). Reading in a second language. Handbook of research in second language teaching and learning, (s 563), 579.

Grabe, W. (1991). Current developments in second language reading research. TESOL Quarterly, 25(3), 375-406. https://doi.org/10.2307/3586977

Grabe, W., \& Stoller, F. (2002). The nature of reading abilities. Teaching and Researching Reading, 9-39.

Güngör, F., \& Yayli, D. (2016). The Interplay between Text-Based Vocabulary Size and Reading Comprehension of Turkish EFL Learners. Educational Sciences: Theory and Practice, 16(4), 1171-1188. https://doi.org/10.12738/estp.2016.4.0078

Hacking, J. F., \& Tschirner, E. (2017). The Contribution of Vocabulary Knowledge to Reading Proficiency: The Case of College Russian. Foreign Language Annals, 50(3), 500-518. https://doi.org/10.1111/flan.12282

Harkio, N., \& Pietilä, P. (2016). The role of vocabulary breadth and depth in reading comprehension: A quantitative study of finnish EFL learners. Journal of Language Teaching and Research, 7(6), 1079-1088. https://doi.org/10.17507/jltr.0706.03

Hu, H. M., \& Nation, P. (2000). What vocabulary size is needed to read unsimplified texts. Reading in a Foreign Language, 8, 689-696.

Kang, Y., Kang, H. S., \& Park, J. (2012). Is it Vocabulary Breadth or Depth that Better Predict Korean EFL Learners' Reading Comprehension?. English Teaching, 67(4).

Laufer, B. (1989). What percentage of text-lexis is essential for comprehension? In C. Lauren \& M. Nordman (Eds.), Special language: From humans to thinking machines (pp. 316-323). Clevedon, UK: England: Multilingual Matters.

Laufer, B., \& Ravenhorst-Kalovski, G. C. (2010). Lexical threshold revisited: Lexical text coverage, learners' vocabulary size and reading comprehension. Reading in A Foreign Language, 22(1), 15.

Li, K. (2015). A study of vocabulary knowledge and reading comprehension of EFL Chinese learners. Studies in Literature and Language, 10(1), 33-40. 
Li, M., \& Kirby, J. R. (2014). The effects of vocabulary breadth and depth on English reading. Applied Linguistics, 36(5), 611-634. https://doi.org/10.1093/applin/amu007

Linan-Thompson, S., \& Vaughn, S. (2007). Based Methods of Reading Instruction for English Language Learners, Grades K-4. ASCD.

Mahmoudi, S., \& Mahmoudi, A. (2017). Can Topic Familiarity Override Language Proficiency in Reading Comprehension?. Journal of Language Teaching and Research, 8(3), 496-506. https://doi.org/10.17507/jltr.0803.07

Mikulecky, B. S. (2008). Teaching reading in a second language. Retrieved from http://longmanhomeusa.com

Moinzadeh, A., \& Moslehpour, R. (2012). Depth and Breadth of Vocabulary Knowledge: Which Really Matters in Reading Comprehension of Iranian EFL Learners?. Journal of Language Teaching \& Research, 3(5). https://doi.org/10.4304/jltr.3.5.1015-1026

Nation, I. (2006). How large a vocabulary is needed for reading and listening?. Canadian Modern Language Review, 63(1), 59-82. https://doi.org/10.3138/cmlr.63.1.59

Nation, I. S. (2013). Learning Vocabulary in Another Language Google eBook. Cambridge: Cambridge University Press. https://doi.org/10.1017/CBO9781139858656

Nation, K., \& Angell, P. (2006). Learning to read and learning to comprehend. London Review of Education, 4(1), 77-87. https://doi.org/10.1080/13603110600574538

Nichols, W. D., Mraz, M., \& Blair, T. R. (2012). Building conceptual understanding through vocabulary instruction. Reading Horizons, 51(4), 299.

Ostyn, P., \& Godin, P. (1985). RALEX: An alternative approach to language teaching. The Modern Language Journal, 69(4), 346-354. https://doi.org/10.1111/j.1540-4781.1985.tb04802.x

Pierce, B. (1994). The test of English as a foreign language: Developing items for reading comprehension. In C. Hill \& K. Parry (Eds.), From testing to assessment: English as an international language (pp. 39-60). New York: Longman.

Qian, D. (1999). Assessing the roles of depth and breadth of vocabulary knowledge in reading comprehension. Canadian Modern Language Review, 56(2), 282-307. https://doi.org/10.3138/cmlr.56.2.282

Qian, D. D. (2002). Investigating the relationship between vocabulary knowledge and academic reading performance: An assessment perspective. Language Learning, 52(3), 513-536. https://doi.org/10.1111/1467-9922.00193

Rashidi, N., \& Khosravi, N. (2010). Assessing the role of depth and breadth of vocabulary knowledge in reading comprehension of Iranian EFL learners. Journal of Pan-Pacific Association of Applied Linguistics, 14(1), $81-108$.

Reed, D. K., Petscher, Y., \& Foorman, B. R. (2016). The contribution of vocabulary knowledge and spelling to the reading comprehension of adolescents who are and are not English language learners. Reading and Writing, 29(4), 633-657. https://doi.org/10.1007/s11145-015-9619-3

Schmitt, N., Jiang, X., \& Grabe, W. (2011). The percentage of words known in a text and reading comprehension. The Modern Language Journal, 95(1), 26-43. https://doi.org/10.1111/j.1540-4781.2011.01146.x

Ulijn, J. M., \& Strother, J. B. (1990). The effect of syntactic simplification on reading EST texts as L1 and L2. Journal of Research in Reading, 13(1), 38-54. https://doi.org/10.1111/j.1467-9817.1990.tb00321.x

Zhang, D., \& Yang, X. (2016). Chinese L2 learners' depth of vocabulary knowledge and its role in reading comprehension. Foreign Language Annals, 49(4), 699-715. https://doi.org/10.1111/flan.12225

\section{Copyrights}

Copyright for this article is retained by the author(s), with first publication rights granted to the journal.

This is an open-access article distributed under the terms and conditions of the Creative Commons Attribution license (http://creativecommons.org/licenses/by/4.0/). 